TRANS · núm. 25.2021

DOSSIER 107-132

La traducción de los religiosos españoles en el siglo xvı alcanzó cimas importantes, tanto por el número de autores, como por la calidad de las obras. Este artículo tiene como objetivo el estudio de los temas de interés, ligados a las preocupaciones sociales, intelectuales y religiosas de la época, y la contribución de los diferentes sectores religiosos en la actividad. Las misiones de ultramar abrieron sin duda nuevas expectativas dentro de esta labor, al tener que enfrentarse a culturas y lenguas desconocidas, lo que resolvieron con soluciones innovadoras y de impacto desde el punto de vista religioso y comunicativo. La metodología empleada en el análisis es de tipo cualitativo y descriptivo. Los resultados obtenidos, que en modo alguno podrían ser exhaustivos, son el producto de una laboriosa investigación en las fuentes documentales y de archivo. La principal conclusión que puede extraerse es que existe una deuda con muchos de estos traductores, injustamente olvidados en la historia de la traducción en España, y que la problemática merece ser tenida en cuenta en la teoría de la traducción, de la antropología y de la filología histórica.

PALABRAS CLAVE: traducción religiosa, traductor, misión, siglo XVı, lenguas indígenas.

\title{
La traducción religiosa en España en el siglo XVI
}

\section{Religious Translation in Spain in the $16^{\text {th }}$ Century}

Antonio Bueno García

Universidad de Valladolid

The translation carried out by Spanish religious people in the $16^{\text {th }}$ century reached important peaks both in the number of authors and in the quality of the works. This article aims to study the topics of interest, linked to the social, intellectual and religious concerns of the time, and the contribution of the different religious sectors in the activity. The overseas missions undoubtedly opened up new expectations regarding this work, since they had to confront unknown cultures and languages, a situation that they resolved with innovative solutions that had an impact from a religious and communicative point of view. The methodology used in the analysis is qualitative and descriptive. The results obtained, which in no way could be exhaustive, are the product of painstaking research in documentary and archival sources. The main conclusion that can be drawn is that there is a debt to many of these translators, unjustly forgotten in the history of translation in Spain, and that the problem deserves to be taken into account within translation theory, anthropology and historical philology.

KEY WORDS: religious translation, translator, mission, $16^{\text {th }}$ century, indigenous language. 


\section{1. INTRODUCCIÓN}

Pasados los tiempos de la era monástica (de los siglos VI al XII), de la reforma cisterciense (siglo XI) y del nacimiento de las órdenes mendicantes (siglo XIII), la península ibérica se enfrentaba desde el ocaso de la Edad Media a una nueva crisis religiosa que alcanzó su punto álgido en el siglo XVI.

El análisis de la traducción de los religiosos ${ }^{2}$ - de sus inquietudes y comportamientosconstituye un escenario privilegiado para comprender la situación social y religiosa y para entender mejor el siglo.

No se ha insistido lo suficiente en que en manos del religioso el oficio genera diferentes expectativas. En efecto, la función del texto se ve influida por la propia condición del traductor, que ofrece su trabajo con la humildad que requiere su profesión de fe, con la obediencia que emana de sus votos (si del clero regular proviene), con su objetivo de contribuir a la salvación de las almas. En trabajos anteriores describimos el concepto de traducción religiosa o monacal (Bueno, 2007). Si la condición del traductor es esencial para comprender el objetivo, igualmente lo son las circunstancias del propio texto. La historia, como fundamento de la traducción, fue puesta ya de relieve hace unas décadas en las aportaciones de teóricos como Levy, Popovic, Meschonnic y muchos otros; y la cultura, como eje moldeador de la historia y de la traducción, fue esclarecida desde los primeros enfoques traductológicos socioculturales de Nida y Taber, y en corrientes posteriores, como el funcionalismo o el polisistema de las que han sido deudoras otras.

\footnotetext{
I Se tiende a considerar como «era monástica» la que transcurre entre la muerte de san Benito (hacia el año 547) y la de san Bernardo (1153), siglos también a los que se les denomina «benedictinos».

2 Para ahondar en la problemática de la traducción religiosa o de los religiosos véase Bueno, 2004.
}

Se impone pues hacer balance de la situación religiosa y de la identidad de la época para comprender mejor la aportación de los traductores religiosos de este siglo, denominado también «de Oro», o «español», donde prenden con fuerza las ideas humanistas y del Renacimiento.

Sorprenderá la profusión de autores religiosos en la época, aunque es adivinable si se tiene en cuenta que la cultura sigue reposando desde la Edad Media en manos de la Iglesia, y que a ellos acuden los nobles y reyes para difundir sus obras o engrandecer su patrimonio cultural.

La amplia tipología textual de los traductores religiosos (no se limitan a los temas teológicos, litúrgicos o eclesiásticos), se deja impregnar por las modas del momento y da entrada a los estilos y temáticas de la época: la novela pastoril, la nueva sensibilidad del humanista-moralista, etc. Algunos de los autores son celebrados por Lope de Vega, como el agustino Fernando de Camargo y Salgado o el eclesiástico Juan de Arjona. También representan a los traductores de su siglo, que traducen tanto por gusto como por encargo, preocupados por la lengua, y oscilando entre la fidelidad a la letra y la felonía frente al original. Lo que habitualmente sí aportan es un estilo propio del predicador, empeñado ante todo en ser comprendido y en persuadir con la palabra; colaborando a su modo con el autor y con el lector.

\section{LA CONDICIÓN DE RELIGIOSO}

En el estudio que aquí acometemos se tiene en cuenta solo a los de la religión cristiana, aunque la condición religiosa en general es muy rica en la península y merecería atención especial en otro artículo. Es necesario también considerar si el acceso a la condición religiosa es vocacional o mero subterfugio de supervivencia social o política (estaba bien visto el acceso a la condición 
eclesiástica en determinadas épocas y situaciones). Así pues, con la cautela que requiere este asunto se analiza la situación religiosa con las claves de la época y se ofrece una antología de traductores y traducciones del siglo. Dado que la traducción bíblica ${ }^{3}$ ocupa un espacio propio en este número, la abordaremos aquí desde una perspectiva más ligera, solo como síntoma de la época y preocupación de algunos religiosos.

En la estratificación del sector religioso distinguimos diferentes grados, que pueden ir desde las órdenes llamadas menores, previas a la ordenación como presbítero, a las mayores, en el caso de la profesión sacerdotal; y diferentes estamentos, como el clero secular, el de la Iglesia diocesana; y el regular, el de las órdenes religiosas. En el último estamento citado advertiremos también la diferencia de vida contemplativa, distinguiendo los frailes de los monjes, según vivan en convento o un monasterio, es decir, si viven en régimen abierto o en clausura.

Aunque no son exactamente religiosas, las órdenes religioso-militares merecen también aquí nuestra atención, pues guardan una relación especial con la Iglesia. Los miembros caballeros o comendadores de estas órdenes hacen también votos canónicos como los miembros de las órdenes religiosas por lo que pueden asimilarse a este grupo. Su creación vino propiciada por la participación en las Cruzadas de sociedades de caballeros cristianos, soldados de Cristo, mitad monjes, mitad soldados, y después con el objetivo de propagar la fe cristiana en Tierra Santa, contra los musulmanes o contra los paganos.

No debe considerarse a los traductores religiosos como un grupo estable, bien avenido $\mathrm{y}$ cohesionado frente al de los traductores laicos, o que el hecho de pertenecer a la Iglesia debe

3 Véanse también, entre otros, los estudios de Cantera (2004) o Lafarga y Pegenaute (2004). traducirse obligatoriamente en afinidad intelectual o incluso religiosa, pues no es el caso: como sucede en todo ámbito humano, la historia de la Iglesia se forja con rivalidades de grupo o de orden, de intereses y alianzas temporales. La Inquisición apuntó de manera muy meticulosa a su labor en esta época. Ante el sistema de evangelización o de difusión de las ideas asistimos a diferentes posturas en el tiempo. Así, por ejemplo, aunque dominicos y jerónimos mostraban una misma preocupación frente a la exégesis de la Biblia (proveniente sobre todo de exégetas de formación hebraísta), al ver desplazarse la autoridad de la Vulgata y la Septuaginta, tuvieron que enfrentarse también dentro de esas órdenes a reacciones heterodoxas surgidas en sus conventos o monasterios. Célebres fueron los conflictos por cátedras entre agustinos y dominicos; también los problemas entre dominicos, agustinos y franciscanos por los procedimientos y circunscripciones de las misiones de América, y de todos ellos con los jesuitas, por ejemplo. La traducción fue sin duda el caballo de batalla en el que más sutilmente se expresaba la discordia.

\section{CLAVES DE LA ÉPOCA}

\subsection{La cuestión de la lengua y de los valores clásicos}

La lengua ha sido para la religión uno de los temas más importantes por su capacidad de poner a la humanidad en contacto con Dios. Desde el episodio de Babel del Antiguo Testamento, hasta el momento en que la Palabra se hizo carne en el Nuevo Testamento o se obra el milagro de Pentecostés, la lengua constituyó el gran tema humano y divino y la esperanza de la comunicación.

En el siglo XVI, cuando se trata de acercar el Evangelio, los religiosos no tienen duda sobre el valor del castellano y suscribirían las palabras 
110 del místico y traductor fray Luis de Granada, que en el Libro de la oración y la meditación plantea como objetivo «hacer contemplativos e perfectos a todos, y enseñar al pueblo en castellano».

Tanto en el orden espiritual como en el temporal, la lengua fue considerada en este siglo un asunto de Estado. Las monarquías europeas basaban su autoridad y su discrepancia con la autoridad de Roma o del emperador cristiano en la singularidad de sus costumbres y de sus lenguas. Sucedió en Europa con el alemán, el inglés, el francés o el italiano; y también en los reinos de España con el castellano, el valenciano, el catalán o el gallego. El vulgar o romance se alzaba así sobre el latín; y lejos quedaban los tiempos en los que la lengua latina era reconocible, incluso para la Iglesia. El desconocimiento había empezado a ser mayúsculo y se imponía una labor de normalización de la lengua vulgar, que terminó dando a la luz gramáticas y diccionarios, aunque se hicieran desde el latín o con el latín como modelo.

El ejemplo de Carlos V, debiendo aprender la lengua de sus ascendientes y súbditos, y defendiéndola además frente a otras, nos parece muy expresivo ${ }^{4}$. El castellano se había convertido ya en lengua nacional.

Y si hablar la lengua vernácula era importante en la época, traducir a la misma también lo era, pues suponía un plus para el reconocimiento político de la nación, de ahí que se viviera como una auténtica carrera la traducción a esa lengua de las ciencias, la filosofía, la teología o literatura.

Pero no solo hubo interés en España por la traducción al castellano, también lo hubo por la traducción a las demás lenguas intrapeninsula-

4 Ruiz Casanova (2018: 139), citando a Brantôme, relata la respuesta del emperador Carlos $\mathrm{V}$ ante una queja del obispo de Mâcon, embajador de Francia, por oírle utilizar el castellano en presencia del papa: «Señor obispo, entiéndame si quiere, la cual es tan noble que merece ser sabida y entendida de toda la gente cristiana». res. El interés de traducir a los clásicos encuentra explicación en la necesidad de consolidar su obra en la lengua emergente, y también en el reconocimiento de la formación humanista y de los valores que emanan de ellos.

El auge del estudio de los clásicos se verifica a partir de los siglos XIII y xIV en Italia, y desde el siglo XIV en España. La imitatio o imitación de los modelos antiguos se pone al servicio de la formación moral y artística del individuo (Christoph Hubig, citado por Ruiz, 2018: 147).

La fecha de 1470, llegada de la imprenta a la península, fue sin duda un momento de inflexión en el panorama bibliográfico y en el lanzamiento de las obras clásicas.

La veneración por el libro y la pasión por la Antigüedad se vive también en las universidades surgidas al amparo de la Iglesia y del beneficio papal, que también desempeñarán un papel protagonista en este proceso. En las cinco disciplinas de los Studia humanitatis: gramática, poética, retórica, filosofía moral e historia, cobrará especial importancia la traducción.

También en la era de los viajes, cuando potencias como Castilla se implantan en el nuevo Mundo y en Asia, la gramática del castellano fue un libro obligatorio en el equipaje, se entendía así como que la lengua era asunto del imperio y símbolo de su cohesión. Aunque la sorpresa fue que los religiosos optaran mayoritariamente por enseñar el Evangelio con ayuda de las lenguas indígenas, por puro pragmatismo religioso (se dieron enseguida cuenta de que de nada servía enseñar la fe si no se les entendía) y que de repente estas ocuparon el trabajo de los misioneros. La elaboración de artes, gramáticas y vocabularios de cientos de pueblos y tribus terminó viéndose como un instrumento más de conquista y la traducción a estas lenguas como garantía de supervivencia en las Indias. Lo que sucedió en América, sucedió igualmente en las Filipinas y 
en Asia Oriental, donde los religiosos no cejaron en el empeño de sistematizar las lenguas en las que realizaron su misión. La traducción a estas lenguas también se sintió como una necesidad del imperio. El español fue la primera lengua de traducción en América y la primera también occidental a la que se tradujo desde el chino ${ }^{5}$.

La labor lingüística y lexicográfica guarda una estrecha relación con la traducción. Al poner el énfasis sobre la lengua, y más aún, cuando se ponen frente a frente varios sistemas lingüísticos, el autor se sirve de la traducción y considera esta como instrumento necesario para su desarrollo.

\subsection{La justificación de la traducción}

Aun cuando no es habitual entre los traductores hacer declaración traductológica, los religiosos que traducen en la época suelen justificar su obra, y lo hacen apoyándose mayoritariamente en san Jerónimo, quien, tras observar la dificultad de la traducción (hablaba de la traducción bíblica) afirma basarse en la búsqueda del sentido. También, en la época de los clásicos, son rememoradas las palabras justificatorias de Virgilio y Cicerón.

Varios son los autores que van más allá en su reflexión y explican las dificultades con ánimo pedagógico, nos referimos a fray Luis de León y a Luis Vives.

Hay una curiosa coincidencia entre el asunto que desencadena la célebre Carta a Panmaquio de san Jerónimo (considerada el sanctasanctórum de la reflexión sobre la traducción del sentido) y el argumento en que basa fray Luis de León su defensa sobre el Cantar de los Cantares. Los dos incidentes que dieron lugar a la polémica parecen cortados por el mismo patrón. Fue

5 Libro chino intitulado Beng Sim Po Cam, que quiere decir Espejo rico del claro corazón, traducido en lengua castellana por el dominico Juan Cobo (1590) e impreso en papel de arroz. para ambos la consecuencia del interés de otro, de un encargo complicado, prohibido, envenenado, que terminó saliendo del circuito íntimo por la acción de manos indiscretas de un individuo sin escrúpulos para sacarlo a la luz con la intención de causar daño al autor de la traducción. En el caso de san Jerónimo, la traducción la hizo por interés personal, y la persona que difundió tal trabajo fue Eusebio de Cremona y un «pseudomónaco» la hizo llegar hasta Jerusalén. En el caso de fray Luis la traducción la hizo para su prima, la monja Isabel de Osorio, y se encargó de su difusión un discípulo del agustino, Diego de León, que copia el manuscrito y llega hasta América $^{6}$.

La explicación que el traductor da sobre la traducción resulta a todas luces también idéntica. Si en el caso de san Jerónimo lo que se discute es la traducción de las Sagradas Escrituras, en las que la salvación y el amor de Dios pretenden hacerse evidentes, en el caso de fray Luis es otro texto sagrado en el que el amor divino alcanza ahora unas cimas eróticas. Ambas traducciones aparecen sometidas al dictamen de la Iglesia, resultando condenada una parte del encargo en el caso del santo, y siendo condenado a la prisión el traductor de la segunda.

El viaje hacia el sentido -idea que aflora en ambos-corrió idéntica suerte, derivando hacia un viaje al ostracismo, a la condena en su tiempo.

Las ideas de fray Luis aparecen en su «Dedicatoria a don Pedro de Portocarrero» (1580), donde el traductor presenta a su amigo la edición manuscrita de sus poesías originales y traducciones, y escribe:

De lo que yo compuse juzgará cada uno a su voluntad; de lo que es traducido, el que quisiere ser juez, prueve primero qué cosa se traducir poesías

6 García de la Concha (1981: 171). Sobre esta cuestión, véase también Marcos Sánchez y Sánchez Zamarreño (1991). 
elegantes de una lengua estraña a la suya, sin añidir ni quitar sentencia, y con guardar quanto es posible las figuras del original y su donayre, y hazer que hablen en castellano y no como estarnjeras y advenediças, sino como nacidas en él naturales. No digo que lo he hecho yo, ni soy tan arrogante, mas helo pretendido hazer, y assi lo confiesso. Y el que dixere que no lo he alcançado, haga prueba de sí, y entonces podrá ser que estime mi trabajo más; al qual yo me incliné solo por mostrar que nuestra lengua recibe bien todo lo que se encomienda, $y$ que no es dura ni pobre, como algunos dizen, sino de cera y abundante para los que la saben tratar (Ruiz, 2018: 222).

Desde el punto de vista teórico, fray Luis de León plantea el respeto escrupuloso por el texto y en el caso de las sagradas Escrituras el innegable valor de la versión hebrea original sobre la de san Jerónimo: de algún modo vendrá a decir que la palabra divina está en el original, no en la versión del santo, y que, en consecuencia, esta debe tomarse como lo que es, una versión del texto, con sus aciertos e imperfecciones, todos imputables al traductor y no al texto original.

Pero desde el punto de vista práctico reconoce la existencia de al menos tres tipos de traducción: «literal» (palabra por palabra), «declaración» (exposición en prosa), y «libre» (en verso castellano).

Presenta su traducción del Cantar de los Cantares como traslado literal del texto hebreo, e insiste en que prefiere, en segundo término, declarar que mudar.

Porque entiendo ser diferente el officio del que traslada mayormente escrituras de tanto peso, del que las explica y declara. El que traslada a de ser fiel y cabal, y si fuere posible contar las palabras para dar otras tantas y no mas, ny menos [...] y el declarar copiosamente la razón que se entiende, y con guardar la sentencia que mas agrada jugar con las palabras añadiendo y quitando a nuestra voluntad (Ruiz, 2018: 225).
La tendencia amplificatoria del traductor es más que obvia en cuanto al número de versos, no así en cuanto al contenido.

Al igual que Arias Montano, el agustino acerca el texto bíblico a la moda de la literatura pastoril de su tiempo.

Lo segundo que pone obscuridad es ser la lengua hebrea (...) de su propiedad y condición lengua de pocas palabras, y de cortas razones y esas llenas de diversidad de sentidos, y juntamente con esto, por ser el estilo y juicio de las cosas en aquel tiempo y en aquella gente tan diferente de lo que se platica ahora, donde hace parecernos nuevas y extrañas y fuera de todo buen primor las comparaciones de que usa este libro, cuando el esposo o la esposa quieren mas loar la belleza del otro, como cuando compara el cuello á una torre, y los dientes a un rebaño de ovejas y así otras semejantes. Como á la verdad cada lengua y cada gente tenga sus propiedades de hablar, adonde la costumbre usada y recibida hace que sea primor y gentileza lo que en otralengua y otras gentes parecería muy tosco (Vega, 1994: 133).

\subsection{La conciencia cristiana en el Humanismo}

La crisis en la que se veía envuelta la Iglesia ${ }^{7}$ hallaba respuesta en la reacción reformista, sobre todo del clero regular y de determinados eruditos, como Erasmo, que propugnaban un retorno al Evangelio. Pero las reacciones tanto de la monarquía como de las elites eclesiásticas no se dejaron esperar: si a finales del siglo xv fueron los judíos y conversos los que perecieron en el intento y debieron huir, en el siglo XVI serán los reformadores luteranos, iluminados y otros herejes los que sucumban en el fuego de los autos de fe.

El Renacimiento no fue un movimiento de optimismo vital, sino una experiencia desde el dolor:

7 Motivada por la decadencia moral y espiritual, que se encontraba lo mismo en los aposentos del papa que en las parroquias y en los conventos. 
la peste negra desde mediados del xiv en España, las guerras como la de los Cien Años entre Francia e Inglaterra, y su repercusión en España - que dio lugar a conflictos sucesorios con epicentro en la familia Trastámara-y las llevadas a cabo en el nombre de Dios, las rebeliones en los campos y en las ciudades, los ajustes de cuentas por la limpieza de sangre y el apartamiento del dogma.

En la corriente humanista se dio sentido a las virtudes de la prudencia, la justicia, la fortaleza, capaces de regenerar a la sociedad cristiana, descubriendo sus fundamentos en la historia, la experiencia y la filosofía moral de las culturas griega y latina.

Lo que el humanismo aportó al religioso fue la convicción de que tenía capacidad para razonar, entender y comprender; al ser creado a imagen de Dios, también podía hacer uso de su juicio para discernir el mensaje del Evangelio, sometido en determinadas ocasiones a la interpretación humana.

Los nuevos valores estaban desde antiguo descritos en las Sagradas Escrituras y la traducción fue, una vez más, necesaria para servir de puente. Pero como sucede siempre en toda aventura traductora, el cambio no pudo venir sin consecuencias: la lengua se convirtió también en caballo de batalla o en caballo de Troya si se prefiere, pues lo que llegó a través de ella terminó impactando las ideas.

¿Qué razones motivaban la traducción de la Biblia y cuáles impedían de facto su versión al romance?

Para empezar, la Biblia, escrita originalmente en lenguas desaparecidas o evolucionadas, arameo y hebreo fundamentalmente, dejó pronto de ser comprensible para los lectores de otro tiempo y cultura. Pero la operación de traducción y la de reinterpretación del sentido ha sido siempre motivo de disputa por las consecuencias sobre la ortodoxia. Lo fue tras su paso al griego con la
Septuaginta, o con el latín en la Vulgata. Los intentos del siglo XVI provocaron serios problemas políticos y religiosos, como el cisma protestante por la versión al alemán, y cuando se realizó en romance. La variación en torno al sentido dado a determinados pasajes atentaba contra los pilares del poder religioso y temporal, que se apoyaban sobre la Biblia.

¿Qué ideas teológicas causaban mayores problemas de interpretación?, ¿y qué impacto tuvieron algunos problemas concretos, como el de la gracia o la conciencia en las ideas expresadas en la traducción?

Desde el siglo v habíamos asistido al debate teológico entre Pelagio y san Agustín. Pelagio sostenía que la gracia divina se evidenciaba en la creación de un hombre dotado de libre albedrío, que tenía discernimiento del bien y el mal, lo que le permitía tomar decisiones libremente. Para Agustín, la gracia era una inspiración divina que se producía en el individuo por mediación de Cristo, y al haber heredado el hombre el pecado original, no existía acto humano capaz de restablecer la relación entre el hombre y Dios, de ahí que Dios hubiera enviado a su hijo para restituir la gracia entre los hombres y hacer posible el perdón y la salvación. La Iglesia reconoció como dogma la posición agustiniana.

Por lo que respecta a la conciencia, las reflexiones se apoyan en san Pablo, quien entendía que los seres humanos tenían esa noción previa, que indicaba a los hombres lo que debían hacer y lo que no. Esta conciencia procede de Cristo y era otorgada a los hombres por medio del Espíritu Santo o de la luz divina. Santo Tomás de Aquino en el siglo XIII declaró que el ser humano tenía una naturaleza racional, dignidad que ninguna otra criatura poseía. Esta capacidad de entendimiento le daba la posibilidad de actuar desde la inteligencia y no desde el instinto y por la misma razón el individuo te- 
114 nía capacidad para rechazar el mal e inclinarse por el bien. Santo Tomás llamó reflexión al acto de autoconocimiento e introspección.

\subsubsection{Reforma y contrarreforma}

La reforma que en España impulsó el cardenal franciscano Francisco Jiménez de Cisneros quiso reducir la corrupción y la ignorancia del clero regular y secular con medidas que no podrían catalogarse de severas: la creación de la Universidad de Alcalá de Henares, un ambicioso programa de educación humanista y el estudio de la Biblia desde las fuentes antiguas (la Biblia Complutense fue su obra magna) parecen lo más sobresaliente; pero no consiguió frenar los anhelos de buena parte de los religiosos de sandalia, que demandaban más rigorismo y medidas más visibles por el pueblo; tampoco las críticas de los sectores más reticentes.

Fue en la primera década del siglo Xvi cuando el fraile agustino Martín Lutero, impregnado del espíritu humanista, regresó a las fuentes del Nuevo Testamento, más precisamente a la Epístola de los Romanos de san Pablo, y concentró sus estudios en san Pablo y también en san Agustín, de quien había aceptado la idea del pecado original y de la salvación (contrapuesta a la de Pelagio). Lutero afirmó que la única justificación posible para los hombres era la fe en Cristo y la gracia divina, y ello por encima de las obras. Dios no era así un juez flexible que pudiese ofrecer la salvación como una recompensa por sus obras meritorias. La humanidad solo podía salvarse por la misericordia de Dios. Las obras debían por supuesto acompañar a la fe, pero no eran la causa de la justificación de la salvación. Los luteranos condenaron además el culto a los santos, la idea de Purgatorio y la venta de indulgencias y bulas papales. También vieron en los sacramen- tos ritos supersticiosos de los que la Escritura no hablaba (salvo el bautismo y la eucaristía ${ }^{8}$ ), y la vía de influencia de los clérigos sobre los fieles.

Erasmo de Rotterdam, cuya obra se enmarca en la idea humanista de la libertad de espíritu, del modelo de virtud (imitación de Cristo) y del pacto $^{9}$ del hombre con Dios, y que tantas traducciones generó en España, defendió también la necesidad de una reforma de la Iglesia y un retorno al Evangelio, a una religión espiritual. En su obra insistió en la solidaridad de la comunidad cristiana (tema paulino del cuerpo místico de Cristo en el que cada miembro forma parte de un cuerpo cuya cabeza era el Hijo de Dios) y en el concepto de reconciliación. En su Diatriba de libero arbitrio, criticó la posición de Lutero y afirmó que la negación en el individuo de su capacidad de poder elegir y tomar sus propias decisiones (libre albedrío) convertía a Dios en un ser cruel e injusto. Del mismo modo, Erasmo distinguió entre la presciencia divina y la predestinación: reconociendo la capacidad divina para conocer el futuro, el humanista holandés afirmó que el acto de pecar dependía únicamente de la voluntad del individuo, lo que le sirvió a Lutero para acusarle a su vez de pelagianismo.

La corriente erasmista gozó del apoyo del emperador. Sin embargo, sus métodos, considerados próximos a Lutero, fueron objeto de críticas por amplios sectores eruditos y eclesiásticos.

El nuevo espíritu reformista religioso prendió también en España, donde surgieron focos protestantes — que desplazaron la traducción a imprentas de Ginebra, de Inglaterra o de otros países donde se extendió la llama-y también

\footnotetext{
8 Tampoco discuten la doctrina de la transustanciación (presencia de Cristo en el sacramento de la eucaristía).

9 La idea de la alianza con Dios se encuentra diseminada en el Antiguo Testamento, que recoge no pocos asuntos del pacto entre Dios y los hombres.
} 
grupos de heterodoxos ${ }^{10}$ dentro sobre todo de las órdenes religiosas, que alarmaron a las autoridades civiles y eclesiásticas, como el de los «alumbrados», que seguían el método místico del «recogimiento», propugnado por los franciscanos y condenado por la propia orden. Los alumbrados afirmaban que actuaban movidos únicamente por el amor de Dios y que de él procedía su inspiración; rechazaban la autoridad de la Iglesia, su jerarquía y sus dogmas, así como las formas de piedad tradicional. Surgieron igualmente las doctrinas del «dejaimiento»y del «quietismo», que excluían toda manifestación visible de amor divino y remitían enteramente a Dios, negando la voluntad - el hombre no tiene voluntad propia y por lo tanto no puede pecar-y mostrándose abiertamente antiintelectuales — no se llega a Dios por la ciencia o la razón, sino por el amor, y el amor de Dios en el hombre es Dios-; de lo que resultó después una ruptura entre «recogidos»y «dejados».

En Trento, tras dieciocho años de disputas teológicas, litúrgicas y jurídicas con la participación del clero secular y regular, no solo se declararon anatema las proposiciones protestantes, sino que se decretaron medidas excepcionales - los decretos doctrinales y decretos de reforma-, como: la obligación de obispos y sacerdotes de vivir en sus diócesis y parroquias; la acumulación de obispados en una sola persona; la predicación del Evangelio de Jesucristo; la asistencia de obispos cada tres años a un sínodo provincial; y el deber de hacer periódicamente visitas episcopales a su diócesis. La centralización de la vida religiosa en torno a la sede obis-

Io Bataillon ha visto en estos grupos (unos 800 según Valera) la influencia del iluminismo erasmista, siendo el más importante el del monasterio jerónimo sevillano (en la población de Santiponce) de San Isidoro del Campo — del que precisamente procedían Cipriano de Valera y Casiodoro de Reina-, y no tanto de la corriente protestante luterana. pal y la llamada a la disciplina del clero secular y regular pretendió reformar las costumbres del clero y también la moral decadente entre los fieles católicos. En cuanto a la definición de la ortodoxia católica, se apoyaron en la tradición escolástica y ganaron fuerza las nuevas ediciones griegas del Nuevo Testamento de Erasmo, al igual que las nuevas traducciones de la Biblia y los textos patrísticos difundidos en las imprentas de Basilea, París, Lyon y Venecia. Rescataron también las ideas agustinianas sobre la regeneración interna del individuo a través de la gracia de Dios, y reconocieron que la persona era libre para elegir entre el bien y el mal. Daban sentido así también a los principios renacentistas de la dignidad del hombre, haciendo de él un individuo responsable de su salvación eterna, y restaurando el valor del mérito y de la libertad humana. Trento rescató también la tradición medieval y validez de los sacramentos y definió las normas sobre los mismos. Y no solo se ocupó Trento de reformar la Iglesia y el catolicismo desde un punto de vista administrativo, moral y doctrinal; también revitalizó algunas prácticas y formas de devoción medievales relacionadas con la redención y salvación eterna: valoró la plegaria, difundiendo nuevas técnicas de oración meditativa y ponderó la actividad caritativa y las obras meritorias. También fomentó nuevas formas de devoción, como la organización de cofradías, el culto a las imágenes sagradas, las procesiones y peregrinaciones, así como la celebración de misas y fiestas religiosas del calendario litúrgico. Todas estas medidas ayudarían a engrandecer el patrimonio espiritual de la Iglesia.

A partir de Trento, una nueva santidad se perfila, que verá indudablemente su reflejo en la actividad traductora: la revisión crítica de las vidas de santos, la profusión de devocionarios, las diversas formas de cultos marianos, los can- 
116 tos y rezos religiosos... Estos cambios mentales y materiales generaron en la sociedad de la época nuevas formas de representación de la religiosidad, que tuvieron consecuencias en la traducción, sentida ahora también como herramienta de la expresión religiosa, y en la actividad textual, que debía dar forma a las diferentes expresiones de la espiritualidad. Podría destacarse que el traductor lego sentiría también, aunque con diferentes matices, el compromiso de la fe (la fe del carbonero); pero el compromiso y la fuerza que imprimen los votos en el clero regular y la autoridad eclesiástica en toda la comunidad religiosa hacen que la traducción sea vista como una herramienta más de servicio a la fe.

\subsubsection{La construcción de la conciencia cristiana en las Indias Orientales y Occidentales}

El descubrimiento del Nuevo Mundo - o el encuentro de dos mundos si se prefiere- representó para el pensamiento humanista una oportunidad para la renovación humana, así como una oportunidad de construir una nueva sociedad cristiana. El escenario que para los misioneros se representaba parecía similar al de los orígenes de la humanidad, o si se quiere previo a la caída de Adán. La desnudez e inocencia de los indios presentaba nuevos retos para los mediadores culturales, traductores e intérpretes en la mayoría de los casos, que aprendieron el oficio desde cero. Atrás quedaba la Reforma o la necesidad de organizar la vida del clero si al final un solo misionero o varios (frailes de algunas de las órdenes religiosas presentes en las expediciones) se responsabilizaba de una tribu y se enfrentaba a su supervivencia. La obligación espiritual que desde Roma ${ }^{11}$ llegó a los reyes de España y de estos a los religiosos viajeros era adoctrinar a los indios en la fe católica y enseñarles las buenas

\footnotetext{
II A través de la Bula Inter Caetera, del papa Alejandro VI.
}

costumbres. Sucesivas bulas permitirían a los misioneros establecerse en diferentes territorios, como la de León X para que los franciscanos pudieran trasladarse a México ${ }^{12}$.

Conforme avanzaron en esta misión se dieron cuenta de que enseñar el Evangelio no podía conseguirse sin superar la frontera lingüística, y ello tanto en el indio como en los misioneros que debían ocuparse de esta labor. De ahí que procedieran enseguida a conocer las lenguas indígenas y a sistematizarlas y catalogarlas en artes, gramáticas y vocabularios para poder hablarles con mayores garantías de comprensión. Así surgieron numerosas obras que daban respuesta a los términos o situaciones expresivas más utilizadas para su ejercicio religioso. Sin entrar en problemas de orden político o jurídico sobre la situación de los administrados, y deteniéndonos en los intereses de la traducción, digamos que esta técnica tuvo que renovarse y partir de una situación que podemos catalogar como «cero» en el ámbito de la comunicación. En efecto, la comunicación lingüística tuvo que partir de una situación inicial de contacto y apoyarse en procedimientos de carácter no verbal e intersemiótico para consolidar el significado o el sentido de las $\cos ^{13}{ }^{13}$. No hubo en un primer tiempo traducción, al menos si estimamos esta desde el punto de vista clásico, porque no se conocía escritura de las lenguas en contacto, aunque sí formas de traducción que podían suplir el inconveniente. Una de las tareas traductográficas más necesarias era dar sentido a su lengua desde la propia de los misioneros. La labor lingüística y lexicográfica es un dominio en el que confluyen el valor de la mediación y el de la consolidación de las lenguas, tareas esenciales de la operación translatoria.

Las lenguas indígenas se sistematizaron desde el modelo de la lengua castellana, que es lo mis-

\footnotetext{
I2 Bula Alias felices.

${ }^{13}$ Véase al respecto Vega Cernuda (2004 y 2013).
} 
mo que decir latina. La fonética (siempre aproximada) obedecía a los criterios de reconocimiento del castellano-parlante. El mestizaje o cultura surgida de varios mundos en contacto, forjó la nueva realidad traductora.

Desde el punto de vista misional y teológico, los religiosos (dominicos, franciscanos, agustinos, jesuitas) seguían, los postulados de sus propias órdenes. La corriente dominica de Salamanca, por ejemplo, defendió la racionalidad de los indios y su capacidad para ajustarse al bien moral de la ley, y se vio este carácter en las obras traducidas para la península. Este pensamiento tuvo su repercusión en las disputas de la metrópoli e impactó en el sistema jurídico de la época. Ahora bien, los frailes tuvieron difícil concienciar a los indios sobre el sentido político, social o religioso de sus ideas y sobre todo del desarraigo de la idolatría. Las herramientas mentales y conceptuales tardarían en poder expresarse. De manera que el Humanismo entró en contradicción con los hechos: no se contó con la diversidad del factor humano (o se había simplificado demasiado la condición humana) ni con el condicionante de la experiencia vital y cultural diferente (lo expuesto no dejaba de ser arbitrario para los indios, que partían de una conciencia moral muy distinta a la occidental o a la cristiana). Los frailes condenaron enseguida los vicios de los indios y vieron también muy complicada y hostil su misión, pero también elogiaron su disposición ante las autoridades y perseveraron en el empeño.

La modificación de los códigos para adaptar al indígena a la moral occidental cristiana siguió un proceso sistemático, y que atiende a las estrategias planteadas por Roselló: predicación, catequización, confesión y educación de los indígenas (2006: 94).

El vínculo entre Dios y su experiencia de la (pan)divinidad debió de hacerse desde nuevos puntos de vista y métodos: catecismos y carti- llas, piezas teatrales, música, fiestas, procesiones, pintura, construcciones arquitectónicas, etc., formas todas para las que se contaba con la inestimable ayuda de la traducción.

La tarea de hacer posible la «revelación» fue sin duda compleja, y el proceso de construcción de una nueva conciencia, laborioso, pero a ese fin contribuyó la traducción. Las obras producidas dan cuenta de todas estos pasos y estrategias. Muchas de estas obras no iban destinadas a los indígenas, sino a los propios misioneros que debían continuar la trayectoria iniciada, y a la metrópoli. El panorama cambió cuando los religiosos fundaron universidades en el suelo americano $o^{14} y$ todos esos textos y otros de talante teológico y científico llenaron sus bibliotecas.

Cierto es que la Iglesia tras la Reforma y la Contrarreforma adoptó como propio el sentimiento del temor a Dios (al que debía implorarse el perdón), la intolerancia ante el pecado y la lucha contra Satanás, y que estos sentimientos se vieron potenciados en los métodos de los misioneros: la lucha contra la tiranía del demonio estará muy presente en el adoctrinamiento de los indios (criaturas vistas en muchos casos como satánicas), como lo ha expresado Roselló (2006: 57-128). Aquí también la diferencia de órdenes religiosas se expresa: si todos transmitieron la idea del amor divino y de un Dios presto a la reconciliación, los franciscanos presentaron un Dios personalizado, bondadoso y comprensivo; los dominicos, un juez todopoderoso e implacable.

Por lo que respecta a los indios, la respuesta fue tan variada como los tipos de pueblos de los que procedían, las regiones geográficas o la clase social a la que pertenecían; también dependió su comportamiento de la orden que los evangelizó o de la lengua en que se había evangelizado.

${ }^{14}$ La primera de ellas, en 1551: Universidad Nacional Mayor de San Marcos, en Lima. 
118 Huelga decir que su sorpresa era mayúscula, al ver que el único interés aparente de estos individuos era hablar de Dios o anunciar a Jesucristo ${ }^{15}$.

No es desatinado decir que las obras de los religiosos influyeron en la conciencia no solo de los indígenas, a los que transmitieron conceptos cristianos de culpa, perdón, reconciliación y salvación, amén de la justicia (divina), sino de la administración política, monárquica y papal, que se vio criticada por el papel jugado en la conquista.

Las tensiones contrarreformistas de Europa fueron también muy evidentes entre los religiosos de ultramar. El papel jugado en el siglo por el Santo Oficio huelga decir que se reprodujo en tierras americanas, y que su larga sombra y atenta mirada se dirigió con celo a las obras y acciones misioneras. Aunque, como sucediera en ocasiones con el latín, la escritura en lenguas indígenas permitió que muchos mensajes pasaran desapercibidos.

Desde mediados del siglo XVI asistimos a la creación por parte de los misioneros de un modelo de sociedad desde cero, para sentirse alejados de la corrupción de la sociedad occidental. Este intento de crear una sociedad ideal, recubierto de un halo utópico se ve claramente en las «reducciones» (del latín reducti, «llevar») de los jesuitas (y antes que ellos, por parte de los franciscanos, de quienes tomaron el modelo), que expresarían el intento de «llevar» a los indígenas hacia el cristianismo. Y si importante fue la labor social y educadora en el poblado indígena, muy importante será también la llevada a cabo con la fundación de universidades en la metrópoli y en los territorios de misión. Fueron sobre todo los dominicos los más activos en la creación de estas instituciones, de ahí que se impusiera el tomismo y también la cultura jurídica de la Escuela dominicana de Salamanca.

I5 La opinión la encontramos en las cartas de viaje del misionero san Francisco de Xavier (Javier, 2017).
El paso de los misioneros españoles desde las Indias Occidentales a las Orientales se hizo posible por dos vías: la española, descubierta tras la expedición desde México a Filipinas de Legazpi, diseñada por el agustino Andrés de Urdaneta en noviembre de 1564, y cuya llegada (militar y religiosa) a las islas Filipinas permitirá también el desplazamiento desde el archipiélago a Asia (la que siguieron agustinos y dominicos, sobre todo); y la portuguesa: que era la ruta marítima de comerciantes entre Europa y Asia, que pasaba por Brasil, África, el océano Índico hasta la India (la que siguió san Francisco Javier).

Lo que los misioneros encontraron en China y Japón fue muy diferente a lo vivido en América. La civilización era mucho más evolucionada y tenía un sistema religioso bien asentado. Los métodos de los religiosos tuvieron necesariamente que variar, pero lo que siguió siendo un pilar esencial para la mediación fue la labor filológica dentro de la misión. La traducción y los estudios lingüísticos sobre las lenguas y culturas originales y de llegada siguieron constituyendo su labor documental esencial.

\section{CONCLUSIÓN}

La traducción de los religiosos españoles en el siglo Xvi fue un escenario relevante para conocer las crisis del siglo y los valores de la nueva sociedad humanista. Además de servir para acercar la cultura grecolatina, respondiendo con sus modelos y virtudes a los problemas de la época, creó nuevas formas de interpretar el Evangelio y generó puentes con culturas sumamente distanciadas, acercando mundos hasta entonces inimaginables.

Aunque el mensaje moral y evangélico constituyó el gran objetivo de la labor traductora, el religioso se puso al servicio de la identificación lingüística y cultural para asegurar el acercamiento entre los pueblos. 
Los métodos utilizados, basados en la labor filológica y antropológica, permiten extraer lecciones de gran valor para la historia y teoría de la traducción.

Pretendiendo crear sociedades desde cero en la misión, los religiosos realizaron un novedoso acercamiento al estado cero de la traducción, el que resulta de una comunicación desde una cultura y lengua desconocidas.

La historia de la traducción tiene una deuda con muchos de estos traductores, injustamente olvidados en las enciclopedias y diccionarios, que tuvieron en sus manos muchos de los textos que forjaron la cultura de la época, y que mostraron gran singularidad a la hora de resolver el problema de la comunicación tanto verbal como no verbal.

\section{TRADUCTORES Y TRADUCCIONES}

El presente listado no pretende ser exhaustivo, habida cuenta de los numerosos textos anónimos, quemados o perdidos en las vicisitudes del siglo, pero sí favorecer el acercamiento a una realidad insoslayable, la de la gran labor llevada a cabo por los traductores religiosos españoles en la metrópoli y allende los mares ${ }^{16}$.

\section{1. Clero secular}

Alonso Fernández de Madrid (arcediano) (siglo XVI)

- Enchiridion o manual del caballero cristiano (1524-1525).

Bernardo de Alderete (Canónigo) (1565-1641)

- Del origen y principio de la lengua castellana o romance que se usa en España (1606).

${ }^{16}$ Para esta descripción resultan muy útiles las obras de Menéndez Pelayo (1953), Roselló (2006), Ruiz (2018) o Russell (1985), además de las obras de Bueno et al. 2005, 2011 y Bueno y Jiménez, 2019.

\section{Bernardo Pérez}

(canónigo de la Catedral de León y de la Colegiata de Gandía)

- Los Silenos, de Erasmo (1529).

- La Lengua, de Erasmo (1531).

- Declaración del Pater Noster, de Erasmo (anónima) (atribuida a él según Bataillon) (1528).

Cristóbal de Mesa (sacerdote) (1556-1633)

- Églogas, de Virgilio.

- Geórgicas, de Virgilio (1618).

- La Ilíada (no se conserva).

- Compendio del Arte poética, de Horacio (en verso).

- Diego López de Cortegana (clérigo) (¿siglos XV-XVI?).

- Querela pacis, de Erasmo.

- El asno de oro, de Apuleyo (1520).

- De curialium miseris (Tratado de la miseria de los cortesanos), del papa Pío II.

- Somnium de Fortuna (Sueño de fortuna), del papa Pío II.

Diego López de Zúñiga (sacerdote) (¿?-1531)

- Biblia Políglota.

Fernán de Oliveira (presbítero) (siglo XVI)

- Grammatica da linguagem portuguesa (1536).

Fernando de Herrera (órdenes menores) (15341597)

- Oda de Horacio.

Francisco Cervantes de Salazar (sacerdote y visitador del Santo Oficio) (entre 1514 y 1518-1575)

- Vergel de sanidad, que por otro nombre se llamava Banquete de cavalleros y orden de vivir (epístola laudatoria en doble versión latina y castellana en L. Lobera de Ávila), (1542).

- Instrucción para ser sabio, de Luis Vives (1544).

- Obras que Cervantes de Salazar ha hecho, glosado y traducido (título general de tres obras) (1546). 
120 - Introducción y camino para la sabiduría (nueva versión de la anterior) "compuesta en latín por [...] Luis Vives, vuelta en Castellano con muchas adiciones”.

- Apólogo de la ociosidad y el trabajo, de Luis Mexía.

- Diálogo de la dignidad del hombre, de Pérez de Oliva.

Francisco de Madrid (arcediano de Alcor, canónigo de Palencia) (¿siglo xv?-1510)

- De los remedios contra próspera y adversa fortuna, de Petrarca (1510).

Gonzalo Correas Íñigo o Gonzalo Korreas Íñigo (sacerdote) (1571-1631)

- Arte de la Lengua Española Castellana (1625).

- Ortografía Kastellana nueva i perfecta (1630).

- Nueva i zierta Ortografía Kastellana (1624).

- Vocabulario de refranes y frases proverbiales (1627).

- Prototypi in graicum linguam Grammatici Canones (1600).

- Trilingüe de tres artes de las tres lenguas Castellana, Latina i Griega, todas en Romanze (1627).

- Vocabulario de refranes (1627).

- Arte Kastellana (1627).

Gregorio Hernández de Velasco (presbítero) (¿1525?-1577 o 1586)

- De partu Virginis, de Sannazaro.

- Versión en octavas reales de La Eneida, de Virgilio (1555).

- Églogas Iy IV, de Virgilio.

- La Eneida, de Virgilio.

Gregorio Morillo (sacerdote, capellán del arzobispo de Granada) (siglos XVI-XVII)

- La Tebaida, de Estacio (acabó los tres últimos libros de la traducción de Arjona).
Hernando Díaz (presbítero) (¿?-después de 1570)

- Grammaticam Chaldaicam (gramática del arameo bíblico o caldeo).

- Variantes al texto caldeo para el Apparatus del tomo viII de la Biblia políglota o regia de Arias Montano.

- Historia de los honestos amores de Peregrino y Ginebra, de Jacopo Caviceo (1527).

Juan de Arjona (eclesiástico, beneficiado de Pinos Puente $\left.{ }^{17}\right)$ (1560-1603)

- La Tebaida, de Estacio.

Juan de Vergara (canónigo de Toledo) (14921557)

- Corrección de la Vulgata para la Biblia Políglota de Alcalá de Henares.

- Traducción de las partes griegas del Antiguo Testamento y los libros sapienciales de la Biblia, incluyendo el Eclesiástico.

- Física, de Aristóteles (inédita).

- De anima, de Aristóteles (inédita).

- Metafísica (gran parte), de Aristóteles (inédita).

Juan del Encina o Juan de Fermoselle (capellán, arcediano y prior de la catedral de León) (1469¿1530?)

- Diez Églogas de Virgilio (1496).

Juan Martín Cordero (sacerdote y nuncio en Amberes) (1531-1584)

- Flores de Séneca, de Erasmo (1555).

- Siete libros de Flavio Josefo (1557), tomados del latín y no del griego original.

- Historia de Eutropio [Flavio Eutropio], Varón Consular (1561).

- Los christiados, de Jerónimo Vida.

- La manera del desafío, de Alciato.

- Declaración de la muerte de Erasmo (1556).

17 En la Iglesia católica «beneficiado» define al presbítero o clérigo que goza de un beneficio eclesiástico. 
- Exhortación a la virtud acomodada a qualquier príncipe christiano de Erasmo (1556), (ambas en el volumen titulado Las quexas y llanto de Pompeyo).

Martín Laso de Oropesa (sacerdote) (1499-1564)

- Farsalia, de Lucano (en prosa castellana) (1530, 1544 y 1578).

- Dos discursos de Cicerón: Pro Marcello y Pro Ligario.

- Carta de Marco Bruto a Cicerón.

Pedro Fernández Villegas (arcediano de la catedral de Burgos) (1453-1536)

- El Infierno de la Divina Comedia, de Dante (1515).

Rodrigo Fernández de Santaella o Maese Rodrigo (clérigo y doctor en Teología) (1444-1509)

- Historia de las grandes cosas maravillosas del mundo, de Marco Polo (1503).

Sebastián de Covarrubias (1539-1613) (Capellán de Felipe II, canónigo de la catedral de Cuenca)

- Tesoro de la lengua castellana o española (1611).

- Sátiras y Epístolas de Horacio (no se han conservado).

\subsection{Clero regular}

\section{ORDEN DE PREDICADORES (OP) O DOMINICOS ${ }^{18}$}

Antonio de los Reyes (siglo XVI)

- Arte en lengua Mixteca (1593).

Bartolomé Roldán (siglo XvI)

- Cartilla y doctrina cristiana por manera de diálogo, traducida, compuesta, ordenada y romanzada en la lengua Cguchona del pueblo de Tepexic de la Seda (1580).

Benito Fernández (siglo XVI)

- Doctrina Mixteca (en dialecto de Tlaxiaco y Achiutla) (1567).

I8 V. Bueno y Jiménez: 2019.
- Doctrina Christiana en lengua Mixteca (en dialecto de Tepuzculula) (1568).

- Vocabulario manuscrito de la lengua Chuchona de Cuextlahuaca.

Diego Carranza (siglo XVI)

- Doctrina cristiana, ejercicios espirituales y sermones en lengua chontal.

\section{Domingo de la Anunciación (1510-1591)}

- Doctrina Christiana breve y compendiosa por vía de diálogo entre su maestro y un discípulo, en lengua castellana y mexicana (1565).

\section{Domingo de Nieva (1562-1607)}

- Arte de la lengua tagala.

- Arte de la lengua china.

- Diccionario español-chino.

- Vocabulario de la lengua china.

- Doctrina Christiana en lengua española y tagala, corregida por los religiosos de las órdenes.

\section{Domingo de Santo Tomás (siglo XVI)}

- Gramática ó arte de la lengua general de los Indios del Pirú (1560).

- Vocabulario de la lengua quichúa.

- Léxico, o Vocabulario de la lengua general del Perú (1560).

Francisco Blancas de San José (siglo XVI -1614)

- Arte de la lengua Tagala.

- Arte para enseñar el castellano á los indios de Filipinas.

- Cantares Espirituales para uso de los indios, en lengua Tagala.

- Memorial de la vida cristiana, en lengua Tagala.

- Preparación para la confesión y comunión, en lengua Tagala.

- De los misterios del Rosario, en lengua Tagala.

Francisco de Alvarado (siglo XVI)

- Vocabulario en lengua Mixteca (1593). 
122 Francisco de Cepeda y Juan de Torres (siglo XvI)

- Artes de los idiomas Chiapaneco, Zoque, Tzendal y Chinanteco (1560).

\section{Francisco Martínez (siglo XVI)}

- Vidas de Santos, en lengua Pangasina.

- Sermones y otros opúsculos, en lengua Pangasina.

Francisco Saravia (siglo XVI -1630)

- Gran Homiliario Chinanteco.

\section{Francisco Viana (¿?-1609)}

- Arte de la lengua de la Vera-Paz.

- Vocabulario y Sermones, en la lengua de la Vera-Paz.

Juan Cobo (1547-1593)

- Arte de la lengua china.

- Catecismo de la doctrina cristina, en lengua china.

- Tratado de astronomía, en lengua china.

- Vocabulario chino-español.

- Beng Sim Po Cam (Espejo rico del claro corazón) (traducción en lengua castellana) (1595).

Juan de Córdova (1503-1595)

- Arte en lengua Zapoteca (1578).

- Vocabulario en lengua Zapoteca (1578).

Juan de Estrada de la Magdalena (Juan de la Magdalena, tras su profesión) (i?-1570)

- Escala Espiritual para llegar al cielo, de San Juan Clímaco (1532).

Juan de Vico (siglo XVI)

- Teología para los Indios, en lengua de Vera-Paz.

- Libro de los grandes hombres, ó Historia de los Patriarcas del Antiguo Testamento, en lengua de Vera-Paz.

- El Paraíso Terrenal, en lengua de Vera-Paz.

- Seis Artesy Vocabularios de diferentes lenguas de los Indios.

- Frases é idiotismos, en lengua de Vera-Paz.
- Poesías sagradas en lengua Cachiquel sobre la Pasión de Nuestro Señor.

- Sermones, en lengua de Vera-Paz.

- Catecismo, en lengua de Vera-Paz.

Juan Núñez (¿?-1647)

- Sermones de doctrina en lengua Chiapaneca.

Juan Ramírez (siglo XVI)

- Santa Doctrina, que es Exposición sobre los Artículos de la Fe, en lengua castellana y mexicana (1537).

- Gramática, en lengua mexicana.

-Vocabulario, en lengua mexicana.

Luis de Granada (Luis de Sarriá, antes de profesión) (dominico) (1504-1588)

- Libro de Menosprecio del Mundo de Kempis (1542).

- Escala Espiritual de San Juan Clímaco (1565), a partir de la traducción latina de Ambrosio Camaldulense.

- Traducción romanzada del Contemptus mundi (hoy conocido como Imitación de Cristo, de Tomas de Kempis) (1536).

Marcos Martínez (siglo XVI)

- Arte de la lengua Utlateca.

Martín de Acevedo (siglo XvI)

- Autos Sacramentales en lengua mixteca.

- Dramas alegóricos en lengua chocha.

Pedro Calvo (1537-1610)

- Gramática y Vocabulario de la lengua de Chiapa.

Pedro de Feria (1524-1588)

- Doctrina Christiana en lengua castellana y zapoteca (1567).

- Arte y vocabulario de la lengua zapoteca.

- Confesionario en lengua zapoteca.

Tomás de Cárdenas (siglo XVI)

- Doctrina cristiana y documentos morales y políticos en lengua Zacapula. 


\section{ORDEN DE LOS HERMANOS MENORES (OFM) O}

\section{FRANCISCANOS $^{19}$}

\section{Agustín Ávila (siglo XvI)}

- Libro de la explicación de la doctrina cristiana en lengua kiche.

\section{Alonso de Molina (1513-1579)}

- Doctrina christiana breve traduzida en lengua mexicana (1547).

- Aquí comiença un vocabulario en la lengua castellana y mexicana (1555).

- Confessionario mayor, en lengua mexicana y castellana (1565).

- Arte de la lengua mexicana y castellana (1571).

- Vocabulario en lengua castellana y mexicana (1571).

- Confessionario breve, en lengua mexicana (1577).

- Cartilla para los niños en lengua tarasca, Grammatica Maturini.

\section{Alonso de Solana (siglo XVI)}

- Vocabulario muy copioso en lengua española y maya (española maya) de Yucatán (1580).

\section{Alonso Rengel (siglo XVI)}

- Artey doctrina cristiana en lengua otomí (1569).

- Arte de la lengua mejicana.

- Cartilla en lengua otomí.

Ambrosio Montesino (¿1444?-1514)

- San Agustín, Meditaciones y soliloquios.

- Breviario de la Immaculada Concepción de la Virgen nuestra Señora (1508).

- Vita Christi cartuxano romanzado, de Ludolfo de Sajonia (4 Vols.) (1502).

- Epístolas y Evangelios por todo el año con sus doctrinas y sermones (1512).

\section{Andrés de Castro (siglo XVI-1577)}

- Artedeaprenderlalenguamatlazinga,deToluca.

- Vocabulariomatlazinga.

- Catecismoy Sermones, en lengua matlazinga.

I9 Véase Bueno et al. (2011).
Andrés de Olmos (1485-1571)

- Arte de la lengua mexicana.

- Vocabulario en lengua mejicana.

- Arte de la lengua guasteca.

- Vocabulario de la lengua totonaca.

- Arte de la lengua totonaca.

\section{Antonio de Ciudad Real (¿1541?-1617)}

- Gran diccionario o Calepino de la lengua maya de Yucatán.

\section{Antonio de los Reyes (siglo XVI)}

- Arte en la lengua misteca (1593).

Benito de Villacañas (siglo XVI -1610)

- Nueva Gramática de la lengua Cachiquel.

- Vocabulario de la lengua Cachiquel.

Bernardino Sahagún o de Sahagún (1499-1590)

- Psalmodia cristiana y Sermonario de los Santos del año, en lengua mexicana, ordenado en cantares o psalmos para que canten los indios en los areytos que hacen en las Iglesias (1583).

- Evangelario en lengua mexicana.

- Sermonario de dominicas y de santos en lengua mexicana.

- Postillas sobre las Epístolas y Evangelios de los Domingos de todo el año.

- Tratado de la Retórica y Teología de la gente mexicana, también náhuatl.

- Arte de la lengua mexicana, con su vocabulario aprendiz.

- Vida de San Bernardino de Siena en náhuatl.

- Vocabulario trilingüe, castellano, latino y mejicano.

- Historia general de las cosas de la Nueva España, en náhuatl y traducida por él también al español (12 libros).

Diego de Landa (1524-1579)

- Arte de la lengua de Yucatán.

- Vocabulario de la lengua de Yucatán.

- Doctrina cristiana en lengua maya (1574). 
124 Diego Ordóñez (siglo XvI)

- Exhortaciones sobre la Penitencia y Comunión, en Lengua de Guatemala.

Diego Ortiz (siglo XVI)

- Sermones en lengua quichúa.

Domingo de Santa María (siglo XvI)

- Arte de la lengua mixteca (antes de 1560).

Francisco de Salcedo (siglo XVI)

- Arte y Diccionario de la lengua mejicana (1575).

Francisco del Toral (siglo XVI)

- Arte y vocabulario de la lengua popolaca.

Francisco Jiménez (siglo XVI)

- Artey vocabulario de la lengua mejicana (1528).

Francisco Jiménez de Cisneros (1436-1517)

- Edición de la Biblia Políglota.

Francisco Marroquín (siglo XVI)

- Catecismo y Doctrina Cristiana en idioma Utlateco (1556).

- Arte ó Gramática de la misma lengua, conforme á la lengua latina.

- Vocabulario de la lengua cachiquel.

- Catecismo ó Doctrina Cristiana en la lengua de Guatemala.

\section{Francisco Parra (siglo XVI -1560)}

- Vocabulario Trilingüe Guatemalteco de los tres principales idiomas Kachiquel, Quiche y Tzutuchil.

Francisco Toral (siglo XVI -1571)

- Arte y Vocabulario de la lengua Totomaca y opúsculos catequísticos en ella.

Jorge de León (siglo XVI)

- Arte de la lengua de Copanabatla.

Juan Baptista (1555-ca. 1613)

- Confesionario en lengua mexicana y castellana (1599).

- Catecismo breve en lengua mexicana y castellana.
Juan Bautista Bravo de Lagunas (1530-1604)

- Arte y Diccionario: con otras Obras en lengua Michuacana, (1574).

- Diccionario tarasco.

- Artey diccionario en lengua Michuacana (1574).

Juan de Acevedo (1551-1624)

- Arte de la lengua de los Yucatanos.

- Miscelánea maya.

Juan de Ayora o Juan de Ahora (Johan Van der Auwera) (¿?-1581)

- Tratado del Santísimo Sacramento en lengua mexicana.

- Arte y Diccionario de la lengua mexicana.

- Arte y Diccionario de la lengua Tarasca.

- Arte y Diccionario de la lengua Illoca de Filipinas.

Juan de Gaona (1507-¿?)

- Coloquios de la Paz y tranquilidad cristiana, en lengua mexicana (1582).

- Sermones dominicales y Tratado de la pasión, en lengua mexicana.

Juan Focher (¿?-1572)

- Arte de la lengua mejicana.

Juan de Guevara (siglo XVI)

- Doctrina christiana en lengua Huasteca (1548).

Juan de Zumárraga (1468-1548)

- Breve y más compendiosa doctrina christiana en lengua mexicana y castellana (1539).

Juan Oliver (siglo XVI -1594)

- Vocabulario de la lengua Tagala.

Julián de Cuartas (siglo XVI)

- Arte compendiado de la lengua maya (1572).

Ludovico de San Francisco (siglo XVI)

- Globus Canonum et arcanorum linguae sanctae (1586).

- Gramática en hebreo. 
Luis Jerónimo de Ore (siglos XVI-XVII)

- Orden de enseñar la doctrina cristiana en las lenguas Quichúa y Aymara (1598).

Luis Rodríguez (siglo XVI)

- Proverbios de Salomón (traducción al náhuatl).

- Eclesiastés (traducción al náhuatl).

Luis Sotelo (i?-1624)

- Catechismus Japonicus.

Luis Vidales (siglo XVI)

- Sintaxis de la lengua maya.

- Vocabulario hispano-maya.

- Vocabulario maya-hispano.

Luis de Villalpando (siglo XVI -1598)

- Arte y vocabulario de la lengua del Yucatán, ó lengua maya.

- Catecismo en lengua maya.

Maturino Gilberti (1498-1585)

- Arte en lengua de Michoacán, lengua tarasca (1558).

- Tesoro espiritual en lengua de Michoacán ó lengua tarasca (1558).

- Diálogo de Doctrina Christiana en la lengua de Mechuacán (1559).

- Vocabulario en lengua de Mechuacán (1559).

- Cartilla para los niños en lengua tarasca (1559).

- Gramática Latina para los Indios (1559).

- Compendio de la gramática latina (1559).

Melchor de Vargas (siglo XVI)

- Doctrina cristiana en castellano, mexicanoy otomí (1576).

Pedro Betanzos (siglo XVI)

- Arte, Vocabulario y Doctrina Christiana en lengua de Guatemala.

Pedro Castillo (siglo XVI)

- Vocabulario de la lengua otomí.

Pedro de Cárceres de Querétaro (siglo XVI)

- Artecilla de la lengua otomí cogida de las migajas de los padres beneméritos della y del cornadi- llo offrecido por el menor de los menores a gloria y alabança de nro. señor Jhu.Xpo. y de la sagrada virgen su sanctissima madre $y$ vitalidad desta pobre gente. (1580).

\section{Pedro de Espinareda (siglo XVI)}

- Arte y vocabulario del idioma de los Zacatecos.

Pedro de Gante (1486-1572)

- Doctrina christiana en lengua mexicana (1553).

- Catecismo en pictogramas.

Pedro Oroz (siglo XVI -1597)

- Arte de la lengua otomí.

Pedro Palacios (siglo XVI)

- Catecismo y Confesionario en lengua otomí.

- Vocabulario mexicano-otomí.

- Arte de la Lengua otomí.

Pedro Sotomayor (siglo XVI -1631)

- Arte, vocabulario y sermones en lengua guatemalteca.

\section{ORDEN DE SAN JERÓNIMO (OSH) O JERÓNIMOS}

Ambrosio de Morales o Ambrosio de Santa Paula (Jerónimo) (1513-1591)

- Discurso sobre la lengua castellana (1546).

- Traducción del griego de la Tabla de Cebes.

Antonio del Corro, jerónimo (¿?-1591)

- Reglas gramaticales (1586).

- Reglas gramaticales para aprender la lengua Española y Francesa (1586) (sin mención del autor, aunque con una dedicatoria por A.D.C., esto es, Antonio del Corro).

- Versión para ingleses de la Gramática española (1590).

- The spanish Grammar, with certains rules, teaching both the spanish and french tongues (1590) (traducción de sus Reglas Gramaticales (Oxford, 1586).

- Eclesiastés (1573). 
126 Casiodoro de Reina (jerónimo, converso al protestantismo y ordenado como pastor de la Iglesia de Inglaterra en 1562 y pastor auxiliar de Fráncfort en 1593) (1520-1594).

- Traducción castellana de la Biblia del Oso (1569).

- Sobre los herejes, de Sebastián Castellion (lo tradujo secretamente).

- Catecismo en latín, francés y neerlandés (1580) .

Cipriano Valera o Cipriano de Valera (jerónimo, converso al protestantismo) (1531/2-¿1602?)

- Revisión Biblia del Oso.

- Biblia del Cántaro (1602) (edición corregida de la Biblia de Reina o Biblia del Oso), con el título: La Biblia. Que es. Los sacros libros del Viejo y Nuevo Testamento. Segunda edición (1602).

- El Nuevo Testamento: que es los escriptos evangelicos y apostólicos revisto y conferido con el texto griego por Cypriano de Valera (1625).

- El Cathólico Reformado, de Perquino (1599).

- Institución de la religión christiana, de Calvino (1597).

Juan Entenio Neclinense (siglo XvI)

- Arte de servir a Dios, de fray Alonso de Madrid, traducido al latín por fray Juan Entenio Neclinense (1521).

\section{Miguel de Comalada (siglo Xvi)}

- Spill de la vida religiosa, escrito en catalán, traducido al castellano y publicado en 1515 .

Miguel de Salinas (siglo XVI)

- Libro Apologético que defiende la docta y buena pronunciación que guardaron los antiguos en muchos vocablos y accentos (1563).

- Tratado para saber bien leer y escribir, pronunciary cantar letras, así en latín como en romance (1551).

- Primera parte de la Ortographia y origen de los lenguajes (1567).
Pedro de Alcalá (siglo Xvi)

- Arte para ligeramente saber lengua arauiga (1505).

- Uocabulista arauigo en lengua castellana (1505).

\section{Pedro de la Vega}

- Historiam, de Tito Livio (1529).

\section{ORDEN DE SAN AGUSTÍN (OSA) O AGUSTINOS ${ }^{20}$}

Agustín de Alburquerque (1529-1580)

- Catecismo tagalo.

- Arte de la lengua tagala.

Alonso de Méntrida (siglo XVI -1637)

- Arte de la lengua hiliguaina de la isla de Panay.

- Bocabulario de lengua bisaia hiligueina, y haraia de la Isla de Panai y Sugbu, y para las demás Islas.

Alonso de Orozco (1500-1591)

- La regla de nuestro gran Padre San Agustín, en latín y en castellano con una breve declaración de algunos lugares que la necesitan.

Benito Caldera Manuel (siglo XvI)

- Las Lusiadas.

Cosme de la Presentación (Cosme Álvarez de Andrade y Payva antes de la profesión) (1550-1580)

- Sermones de Diogo de Payva de Andrade.

Diego Basalenque (Diego Serrano Cardona antes de la profesión) (1577-1651)

- Doctrina cristiana.

- Arte de la Lengua Matlaltzinga mui copioso y assimismo una suma y arte abreviado.

- Arte de la lengua Tarasca.

Diego Muñoz o Diego de San Guillermo (Diego de León y Muñoz antes de la profesión) (1555-1594)

- Sermones místicos.

${ }^{20}$ V. Bueno et al.: 2005. 
Diego Noguera o de Noguera (Diego Pérez Noguera de Valenzuela) (1589-1670)

- Silua de sufragios declarados, alabados y encomendados para comun prouecho de viuos $y$ difuntos.

Diego Ponce (siglo XVI)

- Poenitentia Ninive ad praedicationem Jonae pro Adventu dicenda.

Esteban Marín (siglo XVI -1601)

- Arte de la lengua zambala y española.

Fernando de Camargo y Salgado o Hernando de Camargo (1572-1652)

- Completas de la Vida de Christo S. N. cantadas al harpa de la Cruz por el mismo.

- El Ángel de la Guarda.

- La Universal Conspiración de la Correa.

- Oratorio sacro de Soliloquios, y varias devociones de Nuestra Señora.

- Quaresma del Padre Maestro Fray Ivan de Ceyta, portugués, de a Orden Serafica, con un Sermon admirable al fin, del auto de la Fe, contra los Iudios.

- Relación del milagro del Sto. Cristo que está en Goa, en el convento de Sta. Mónica de Monjas Agustinas, que habló por ocho días seguidos.

- Revelaciones de Sta. Brígida.

- Sermones de Christo y su Madre, y del Santissimo Sacramento.

Francisco de Acosta (1523-1605)

- Arte de la lengua Pirinda.

Juan Quiñones (siglo XVI)

- Arte y Vocabulario de la lengua Tagala (1581).

Juan Bautista Montoya o de Montoya (siglo XVI -1622)

- Catecismo.

Juan de la Anunciación (Juan Fernández Herrera) (1514-1594)

- Doctrina Christiana muy cumplida, donde se contiene la exposición de todo lo necesario para
Doctrinar a los Yndios, y administralles los Sanctos Sacramentos. Compuesta en lengua castellanay mexicana (1575).

- Sermones para publicar, y despedir la Bulla de la Sancta Cruzada, compuestos y traduzidos, en lengua mexicana y castellana (1575).

- Sermonario en lengua mexicana, donde se contiene (por el orden del Missal nuevo Romano), dos sermones en todas las Dominicas y Festividades principales de todo el año en las Fiestas de los Sanctos, con sus vidas, y comunes. Con un Cathecismo en lengua mexicana y Española, Breve y muy compendioso, para saber la doctrina cristiana y enseñarla (1577).

- El Catecismo de Fr. Juan de la Anunciación, O.S.A. (1577).

- Gramática mexicana.

Juan de la Cruz (¿?-1574)

- Doctrina christiana en la lengua guasteca con la lengua castellana, la Guasteca.

- correspondiente á cada palabra de guasteco (1571).

- Arte de la lengua guasteca.

Juan de Medina Rincón (1520-1588)

- Doctrinalis fidei in Mechoacanensium Indorum lingua editus (en lengua tarasca) (1577).

- Tesoro espiritual de los pobres en lengua de Michuacán (1575).

- Doctrinalis fidei in michuacanensium induorum linguam (1575-1578).

Juan González de Criptana o Juan de Critana (Juan de Soria Lupesia) (s. XVI)

- Forma breve de rezar con los misterios de la vida, pasión y glorificación de Jesu Christo nuestro Señor y de su madre Santísima la virgen Nuestra Señora.

Juan Martínez (Juan Martín de Ormaechea) (s. XVI-1616)

- Vocabulario en la lengua general del Perú llamada Quichua, y en la lengua Española. 
128 Julián Macho (siglos XV-XVI)

- Le miroir de vie humaine.

- Les Fables de Esope.

Luis de León (agustino) (1527-1591)

- Cantar de los Cantares (1580).

- Libro de Job.

- El libro de los Proverbios.

- Eclesiastés.

- Sabiduría, de Salomón.

- Salmos.

- Exposición del Psalmo L. Miserere mei Dues etc. Traducción en verso castellano con una canción a Cristo crucificado.

- Traducción del Psalmo Benedic anima mea Domino. («Alaba a Dios contino o alma mia...»).

- Traducción del Pange Lingua y juntamente con un Salmo y Vida Solitaria.

- Églogas de Virgilio (diez).

- Geórgicas (los dos primeros libros).

- Bucólicas.

- Odas de Horacio (oda X del libro II).

- Oda I de las Olímpicas de Píndaro.

- Elegía III del libro II de Tibulo.

- Canzione I de Giovanni della Casa.

- Andrómaca de Eurípides (algunos dísticos).

- La Odisea (algunos versos).

- Eneida (los seis primeros libros).

- Algunas imitaciones y recreaciones de temas, motivos y obras poéticas de Petrarca, Pietro Bembo, Ausonio, Ovidio, etc.

Martín de Rada (1533-1578)

- Arte de la lengua otomí.

- Arte y vocabulario de la lengua cebuana.

- Arte y Vocabulario de la lengua china.

Melchor de Vargas (siglo XVI)

- Doctrina Christiana, muy util y necesaria en Castellano, Mexicano y Otomí.

Pedro Malón de Echaide o Chaide (agustino) (1530-1589)

- Salmos.

\section{COMPAÑÍA DE JESÚS (SJ) O JESUITAS}

Alonso Barzana, Alonso de Bárcena o Alfonso de Bárcena (1530-1597)

- Doctrina christiana, y catecismo para instrucción de los Indios y de las demás personas, que han de ser enseñadas en nuestra sancta Fe. Con un conffessionario, $y$ otras cosas necesarias para los que doctrinan, que se contienen en la página siguiente. Compuesto por auctoridad del Concilio Prouincial, que se celebró en la Ciudad de los Reyes, el año de 1583, y por la misma traduzido en las dos lenguas generales, de este Reyno, Quichua y Aymará (1583).

- Arte y vocabulario en la lengua general del Peru llamada Quichua, y en la lengua española.

- Confessonario para los curas de Indios. Con la instrucción contra sus Ritos: $y$ Exhortacion para ayudar a bien morir: y summa de sus Privilegios: y forma de impedimentos del Matrimonio. Compuesto y traducido en las lenguas Quichua, y Aymara. Por autoridad del Concilio Prouincial de Lima (1583).

- Lexica et praecepta grammatica, item liber confessionis et precum in quinque Indorum Linguis (1590).

- Arte y vocabulario de la lengua toba.

- Tercero Cathecismo y exposición de la Doctrina Christiana, por Sermones. Para que los curas, y otros ministros prediquen y enseñen a los indios y a las demás personas. Conforme a lo que en el Sancto Concilio prouincial de Lima se proveyó (1585).

- Rituale, seu Manuale Peruanum, et forma brevis strandi apud Indos sacrosancta Baptismi, Poenitentiae, Eucharistiae, Matrimonii, et Extremae unctionis Sacramenta. Iuxta ordinem Sanctae Romanae Ecclesiae. Per R.P.F. Ludovicum Ieronymum Orerium, Ordinis Minorum Concionatorem, et Sacrae Theologiae Lectorem accuratum: et quae indigent vesrione, vulgaribus Idioma- 
tibus Indicis, secundum diversos situs omnium Provinciarum novi orbis Perù, aut per ipsum translate aut eius industria elaborate (1607).

- Arte, catecismos y algunos sermones, en lengua Guaraní.

- Arte, catecismos y algunos sermones, en lengua Natixa.

- Arte, catecismos y algunos sermones, en lengua Quiroquiní.

- Arte y vocabulario de la lengua de los Querandies.

- Catecismo y algunos sermones en Abipón.

- Arte y Vocabulario de la lengua Tonocoté.

- Arte y Vocabulario de la lengua Kakana.

- Arte y Vocabulario de la lengua Puquina.

- Explicación del Catecismo distribuida en Homilías y Sermones, compuesta por el P. Barzana en la lengua castellana, y traducida por el mismo a las lenguas Quechua, Puquinica, Tonocática, Catamarcana, Natixana o Mogoznana y Guaranítica.

- Método para administrar y recibir con fruto el Sacramento de la Penitencia, compuesto por el P. Barzana primeramente en lengua Quechua, y traducida después por él mismo a las lenguas Tonocótica, Catamarcana, Natixana, Puquínica y Guaraní.

\section{Antonio del Rincón (siglo XVI)}

- Arte Mexicana (1595).

\section{Bartolomeo Bravo (1554-1607)}

- Diálogo de la Concepción de Nuestra Señora, en castellano y latín, representado en Monterrey en 1578.

- Thesaurus verborum ac phrasium ad orationem latine efficiendam et locupletandam (Salamanca, 1599.

- Thesaurus hispano latinus utriusque linguae dives opum (Valladolid, 1654).

\section{Diego Ruiz de Montoya (1562-1632)}

- Arte, vocabulario, tesoro y catecismo de la lengua guaraní.
Enrique Enríquez (siglo XVI -1600)

- Gramática, en lengua de Comorin.

- Vocabulario, en lengua de Comorin.

- Doctrina cristiana, en lengua de Comorin.

- Confesonario, en lengua de Comorin.

- Flos sanctorum, en lengua de Comorin.

Francisco de Xavier (1506-1552)

- Catecismo, en lengua paraba.

- Oraciones en lengua malaya: el Credo, con una declaración sobre los artículos; la confesión general; Pater Noster; Ave María; Salve Regina; y los Mandamientos de la ley.

- Doctrina cristiana, en lengua de Japón (con Angeró).

- Libro con la creación del mundo, la vida de Cristo y la declaración del día del juicio, en lengua de Japón.

Francisco Hernández (¿?-1602)

- Catechismus in modum dialogi, en lengua bengalí.

\section{Francisco Ros (1557-1624)}

- Doctrina cristiana o Catecismo, s. 1., s. f. (en lengua malabar).

- Ritus Baptizandi, Inungendi infirmos, nupcias celebrando e latina in Syruacam convertir, in usum Pariochorum Angamalensium, s. 1., s. f. (en lengua siriaca).

- Missalia, Breviario, Ritualia, aliosque libros Ecclesiasticos e ritu Romani in Chaldaicam linguam transtulit, s. 1., s. f. (traducidos del latín a la lengua caldea).

- Quinquaginta Canones Concilii Nysseni, in chaldaicam linguam transtulit, s. 1., s. f. (traducido a la lengua caldea).

Gaspar de Villela ( $\left.\_-1572\right)$

- Varios libros piadosos traducidos al japonés.

José de Anchieta (1534-1597)

- Arte da lingoa mais commun do Brazil (1595).

- Arte de gramática de lingua mais usada na costa do Brasil. 
130 - Dictionarius linguae Brasilicae.

- Doctrina Christiana, pleniorque Catechismus eadem lingua explicatus.

- Instrucción para auxiliar á los moribundos.

- Confesionario.

- Na Vila de Vitéria e Na visitaçao de Santa Isabel, rpeças en castellano y portugués.

- O Poema da Virgem, trad. De Beata Virgine Mater Dei Maria con ritmo de A. Cardoso.

- Poemas eucarísticos e otros, con trad. del latín.

Juan de Azpilcueta (siglo XVI-555)

- Algunas oraciones y diálogos catequísticos.

Juan de Mariana (1536-1624)

- Compendio y traducción en latin de la Biblioteca Griega de Phocio (s. XVII).

Juan Fernández (siglo XVI)

- Grammatica linguae Japonicae

Luis de Azevedo (1573-1634)

- Traducción al etíope (copto) del Nuevo Testamento.

- Las horas de la Virgen (en colaboración con Luis Caldeira).

- Gramática de la lengua etíope.

- Traducción al caldeo de los Comentarios de Francisco de Toledo á la Epistola de San Pablo á los Hebreos.

- Traducción al caldeo de las Horas canónicas.

- Traducción al caldeo de Las Horas de la Virgen.

Luis Bonifaz (1578-1644)

- Arte de la lengua principal de Sinaloa.

Pedro de Rivadeneira (1526-1611)

- Biografía de San Ignacio de Loyola, en latín (1572) y en castellano (1583).

- Las Confesiones del glorioso doctor de la Iglesia San Agustín, traducidas de latín en castellano (1596).

\section{ORDEN DE SAN BENITO (OSB) O BENEDICTINOS}

Alonso de Virués (1493-1545)

- Coloquios familiares, de Erasmo.

Alonso de Virués (1493-1545)

- Coloquios de Erasmo (1529).

ORDEN DE NUESTRA SEÑORA DEL MONTE CAR-

MELO (OCARM) O CARMELITAS

Elías de San Juan Bautista (siglo XVI -1605)

- Diálogos en lengua Mexicana (1598).

- Compendio de las Excellencias, de la Bvlla de la Sancta Cruzada, en lengua Mexicana (1599).

Gabriel de Aulón (siglo XVI)

- Coloquios de Vives (1574).

Gerónimo Gómez de Huerta o Jerónimo Gómez de la Huerta (¿1573-1643?)

- Historia natural de Cayo Plinio Segundo (traducción de los primeros libros).

Juan Tadeo de San Eliseo (1574-1634)

- Traducción del libro de los salmos al persa, Memoria de los cristianos que en la Persia han bautizado los padres carmelitas descalzos (16071621).

- Kalendariumn scientificum persicum, escrito en latín y persa.

- Traducción de los cuatro Evangelios al persa, Doctrina espiritual... traducida al persa.

- Relación de la misión de los carmelitas descalzos que la santidad de Clemente octavo envió al reyy reinos de Persia.

María de San José (Salazar) (1548-1603)

- Instrucción de novicias (autotraducción al francés) (1602).

\section{ORDEN DEL CISTER (OCIST) O CISTERCIENSES}

Cipriano de la Huerga (¿1509?-1560)

- Partes del Libro de los Salmos según el texto hebreo, aunque se han perdido.

- Edición corregida de la Biblia de Reina (1602). 
Cristóbal de Castillejo (cisterciense) (1490-1550)

- Parafraseó y utilizó en su propia obra lírica versos de Catulo.

- Fragmentos de las Metamorfosis de Ovidio de Ovidio (el «Canto de Polifemo», la «Fábula de Acteón» y la «Historia de Píramo y Tisbe» (1528).

- Tratados de Cicerón De senectute y De amicitia.

- Se le atribuye también una traducción de los Amores de Ovidio (1598).

\section{ORDEN DE SANTIAGO}

Benito Arias Montano (sacerdote de la Orden de Santiago) (1527-1598)

- Tratado de Retórica (1572).

- Obras lingüísticas contenidas en la Biblia Políglota: diccionario y gramática griegos, vocabulario siríaco debido a Andreas Masius (Maes), gramática siríaca, diccionario siro-arameo debido a Guido Lefèvre de la Boderie.

- Thesaurus hebraicae-linguae de Sanctes Pagninus en latín.

- Supervisión de la Biblia Políglota (1571) (también conocida como Biblia Regia o Biblia de Amberes).

- Biblia Sacra (Biblia sacra hebraice, chaldaice, graece et latine, Philippi II. Reg. Cathol.pietate, et studio ad sacrosanctae ecclesiae usum Christoph. Plantinus excud. Antverpiae (8 volúmenes impresos entre 1569 y 1573).

- Traducción del hebreo al latín de los Salmos (1573).

- Traducción del hebreo al latín del Itinerarium Beniamini Tudelensis (1575) (considerado un "epítome" por Arias Montano, pues el libro completo se hallaba en Egipto).
- Traducción no impresa del Comentario de David Quimi a algunos Profetas, en parte en español y en parte en latín ${ }^{21}$ (Sáenz-Badillos, 1997: 349).

- Odas latinas.

Hernán Núñez de Toledo y Guzmán (comendador de la Orden de Santiago) (14781553)

- Biblia Políglota (griego).

- Censura de la versión latina del texto de la Septuaginta para la Biblia Políglota Complutense.

- Refranes o proverbios en romance (1555).

- Traducción al castellano de la Historia de Bohemia, de Enea Silvio Piccolomini (1509).

- Epístola A los muchachos cristianos, de San Basilio (con texto griego y latino).

\section{REFERENCIAS BIBLIOGRÁFICAS}

Bueno García, Antonio (ed.) (2004): La traducción en los monasterios, Valladolid: Universidad de Valladolid.

Bueno García, Antonio (2007): «Claves para una teoría de la traducción. Perspectiva desde la labor agustiniana», en Antonio Bueno García (ed.), La labor de traducción de los agustinos españoles, Valladolid: Editorial Estudio Agustiniano, 17-40. También en forma de conferencia en: <https://www.youtube.com/watch?v=14RZh_ HmPFo\&list=PLYCQO6-9yHlK9Dybf7yDk7vz7W_ 3TT4jy\&index $=18>$.

Bueno García, Antonio, Cristina Adrada Rafael y Rocío Anguiano Pérez (2005): Catálogo biobibliográfico de traductores, lexicógrafos y escritores en lengua extranjera agustinos españoles (edición electrónica), Valladolid: Estudio Agustiniano, con la colaboración del Ministerio de Educación y Ciencia, Fondo Europeo de Desarrollo Regional -FEDER- y Grupo de Investigación

${ }^{21}$ En SÁENZ-BADILLOS, Angel. 1997. Benito Arias Montano, hebraísta. Thélème: Revista complutense de estudios franceses, no 12 , pp. 345-359. 
132 Traducción Monacal -UVA). También en: <https:// agustinos2002.files.wordpress.com/2020/08/ libro-catalogo-agustinos-4.pdf $>$.

Bueno García, Antonio, Elena Irene Zamora Ramírez, Ana María Mallo Lapuerta y Eleuterio Carracedo Arroyo (2011): Catálogo bibliográfico de traductores, lexicógrafosy escritores en lengua extranjera franciscanos españoles. Introducción Antonio Bueno García (edición electrónica), Madrid: Editorial Cisneros, con la colaboración del Ministerio de Ciencia e Innovación, Proyecto FFI2008-00719/FILO «Catalogación y estudio de las traducciones de los franciscanos españoles». También en: <http://www.traduccionfranciscanos.uva.es>.

Bueno García, Antonio y Elena Jiménez García (2019): Catálogo bibliográfico de traductores, lexicógrafos $y$ escritores en lengua extranjera dominicos españoles $e$ iberomericanos. Introducción Antonio Bueno García (edición impresa), Granada: Editorial Comares (Publicación efectuada en el marco del Proyecto nacional de Investigación, financiado por el Ministerio de Economía, Industria y Competitividad (Gobierno de España), Ref.: FFI2014-59140-P «Catalogación y estudio de las traducciones de los dominicos españoles e iberoamericanos».) También en: <http://traduccion-monacal.uva.es/ catalogo-bibliografico-de-traductores-lexicografos$y$-escritores-en-lengua-extranjera-dominicosespanoles-e-iberoamericanos/>.

CANTERA, Jesús (2004): «Antiguas versiones latinas de la Biblia y su repercusión en las traducciones al español», en Antonio Bueno García (ed.). La traducción en los monasterios. Valladolid: Universidad de Valladolid, 43-61.

García DE LA Concha, Víctor (1981): «Fray Luis de León: Exposición del Cantar de los Cantares», en Víctor García de la Concha (ed.), Academia Literaria Renacentista. I. Fray Luis de León, Salamanca: Universidad de Salamanca.

JAVIER, San Francisco (2017): Textos escogidos de San Francisco Javier: Cartas de viaje, Bogotá: Pontificia Universidad Javeriana.

LAfArga, Francisco y Luis Pegenaute (eds.) (2004): Historia de la traducción en España, Salamanca: Editorial Ambos Mundos.
Marcos Sánchez, María de las Mercedes y Antonio Sánchez Zamarreño (1991): «Fray Luis y su Exposición del Cantar de los Cantares: por las rutas de una vocación literaria», en Saturnino Álvarez Turienzo (ed.), Fray Luis de León. El fraile, el humanista, el teólogo, El Escorial: Ediciones Escurialenses, 765-784.

Menéndez Pelayo, Marcelino (1953): La ciencia española, ed. E. Sánchez Reyes, Santander: C. S. I. C., recoge las modificaciones de la $3^{\mathrm{a}}$ ed., de 1887.

Pellicer y SAforcada, Juan Antonio (1778): Ensayo de una bibliotheca de traductores españoles, Madrid, Antonio de Sancha.

Roselló Soberón, Estela (2006), Así en la tierra como en el cielo: manifestaciones cotidianas de la culpa y el perdón en la Nueva España de los siglos XVI y XVII, México: El Colegio de México. <https://www.jstor. org/stable/j.ctv47w9fb.5?seq=32\#metadata_info_ tab_contents $>$.

Ruiz Casanova, José Francisco (2018): Ensayo de una historia de la traducción en España, Madrid: Cátedra.

RusSELL, Peter E. (1985): Traducciones y traductores en la Península Ibérica (1400-1550), Bellaterra: Universidad Autónoma de Barcelona.

SÁENZ-BADILlos, Ángel (1997): «Benito Arias Montano, hebraísta», Thélème: Revista complutense de estudios franceses, 12, 345-359.

Vega Cernuda, Miguel Ángel (1994): Textos clásicos de teoría de la traducción, Madrid: Cátedra.

Vega Cernuda, Miguel Ángel (2004): «Lenguas, farautes y traductores en el encuentro de los mundos. Apuntes para una historia de la comunicación lingüística en la época de los descubrimientos en la América protohispana», Hieronymus Complutensis, 11, 81-108.

Vega Cernuda, Miguel Ángel (2013): «Momentos estelares de la traducción en Hispanoamérica», $M u$ tatis Mutandis, 6/1, 22-42. 